\title{
Encapsulation of live cells by metal-organic frameworks for viability protection
}

\author{
Chao Sun ${ }^{1 \dagger}$, Lin Chang ${ }^{2 \dagger}$, Ke $\mathrm{Hou}^{2}$, Shaoqin $\mathrm{Liu}^{3}$ and Zhiyong Tang ${ }^{1,2^{*}}$
}

\begin{abstract}
In this study, a yeast@ZIF-8 core-shell composite material was successfully synthesized under room temperature in aqueous solution. The ZIF-8 shell endowed the inner yeast cells with a considerably extended lifetime without any nutrients at $4^{\circ} \mathrm{C}$. Compared with the bare yeast cells, most coated yeast cells were kept alive even when cultured in zymolyase solution for $3 \mathrm{~h}$. Furthermore, the encapsulated yeast cells could be reactivated and regrown by dissolving the ZIF-8 shell with competitive coordination interactions.
\end{abstract}

Keywords: live cells, ZIF-8, viability protection

\section{INTRODUCTION}

Nowadays, a large number of food security accidents are being reported worldwide, and among these accidents, the vaccine expiration problem is the most eye-catching case. A vaccine would likely lose its protective effect or be harmful to the human body if its biological structure is damaged or denatured by temperature or metal ions. Typically, there are four steps involved in vaccine usage from the factory to the human body, including production, shipment, distribution and injection, and each step can result in a loss of the viability of the vaccine. Therefore, new surface coating techniques are highly desirable for preserving the metabolic activity of vaccines $[1,2]$.

Currently, numerous bioactive substances, including vaccines [3], yeasts [4-6], and tobacco virus [7] as well as mammalian cells $[8,9]$, have been successfully coated with materials such as graphene [10], calcium carbonate $[11,12]$, titanium-silicon composites [13], or even nanoparticles with different morphologies [14,15]. Among the chosen materials reported, metal-organic frameworks (MOFs) [16-18], a type of crystalline material constructed with metal ions or metal clusters and organic ligands, have attracted the most attention because of their porous structures, diversity of precursors, and convenient synthesis [19-21]. Several materials [22-24] and semiconductors [25-27] of different sizes and shapes have been coated with MOFs to form composite materials. In addition, some biological macromolecules, such as proteins [28-30], enzymes [31-36], and cells $[37,38]$, have been coated with MOFs under mild conditions, which is critical for the maintenance of their biological activity. Nevertheless, only few studies have reported on the encapsulation of cells by MOFs. Further studies are highly needed, for instance, to evaluate the heterogeneous growth mechanism of MOFs on cell surfaces and the emerging properties of these composite materials.

In this study, the encapsulation of yeast cells by zeolitic imidazolate framework (ZIF-8) - a typical MOF-under room temperature was reported and the protective effect of the ZIF-8 shell on yeast cells under harsh external conditions was highlighted.

\section{EXPERIMENTAL SECTION}

\section{Synthesis of yeast@ZIF-8}

Yeast cells $(4.5 \mathrm{mg})$ in yeast extract peptone dextrose medium were centrifuged at 3,000 rpm for $5 \mathrm{~min}$ each time and then washed thrice with deionized (DI) water. After centrifugation, yeast cells were suspended into $1 \mathrm{~mL}$ of $0.05 \mathrm{~mol} \mathrm{~L}^{-1}$ zinc nitrate aqueous solution, and $1 \mathrm{~mL}$ of $0.2 \mathrm{~mol} \mathrm{~L}^{-1} 2$-methylimidazole aqueous solution was then added to the solution. After the reaction was proceeded on an orbital shaker $(300 \mathrm{rpm})$ at $30^{\circ} \mathrm{C}$ for $1 \mathrm{~h}$, the product was collected and washed thrice with DI water.

\footnotetext{
${ }^{1}$ School of Material Science and Engineering, Harbin Institute of Technology, Harbin 150001, China

${ }^{2}$ CAS Key Lab of Nanosystem and Hierarchy Fabrication, National Center for Nanoscience and Technology, Beijing 100190, China

${ }^{3}$ State Key Laboratory of Urban Water Resource and Environment, Harbin Institute of Technology, Harbin 150090, China

† These authors contributed equally to this work.

* Corresponding author (email: zytang@nanoctr.cn)
} 


\section{Cell viability experiment}

Encapsulated and bare yeast cells were suspended in $5 \mathrm{~mL}$ DI water at $4^{\circ} \mathrm{C}$, and a certain volume of the samples was regularly collected to test their viability using fluorescent molecular probes. The FUN 1 stain showed that metabolically active cells were clearly marked with orange-red fluorescent intravacuolar structures, whereas dead cells exhibited extremely bright, green-yellow fluorescence. The typical process used in our experiment is described below. Yeast cell solution $(2 \mathrm{~mL})$ with nutrients was centrifuged and washed thrice with DI water at 3,000 rpm for $5 \mathrm{~min}$ each time. Subsequently, samples were suspended into $1 \mathrm{~mL}$ of $0.3 \mathrm{~mol} \mathrm{~L}^{-1} \mathrm{NaCl}$ aqueous solution, and $0.5 \mu \mathrm{L}$ FUN 1 was then added. Protected from light, the sample was then incubated for $30 \mathrm{~min}$ at $30^{\circ} \mathrm{C}$ before observation under a confocal microscope. The cells were then washed thrice with DI water to remove free dye in the solution.

Alexa Fluor 647 was also used to stain the ZIF-8 shell because pores inside the ZIF- 8 shell can adsorb the fluorescent dye molecules. The stain process was very similar to the FUN 1 stain process. An appropriated amount of dye was mixed with the samples in the dark for $30 \mathrm{~min}$ at $30^{\circ} \mathrm{C}$ before observation using confocal laser scanning microscopy (CLSM).

\section{Zymolyase assay}

Zymolyase was widely used as a cell lytic enzyme for cell wall digestion and always used for survival test. The tested sample was centrifuged and resuspended in $5 \mathrm{~mL}$ of $50 \mathrm{mmol} \mathrm{L}^{-1}$ phosphate buffer saline ( $\mathrm{pH}$ 7.5). The samples were then treated with zymolyase $\left(0.1 \mathrm{mg} \mathrm{mL}^{-1}\right)$ and incubated at $30^{\circ} \mathrm{C}$ on the orbital shaker. The survival of yeast cells was monitored via FUN 1 staining of the samples.

\section{Cell proliferation experiment}

Before the cell proliferation experiment, the ZIF-8 shell was removed by adding disodium ethylenediamine tetraacetate (EDTA) solution $\left(0.1 \mathrm{~mol} \mathrm{~L}^{-1}, \mathrm{pH} 7\right)$ into the yeast cell solution. Both the bare and reactivated yeast cells were suspended in $0.1 \mathrm{~mL}$ of yeast extract $\left(10 \mathrm{mg} \mathrm{mL}^{-1}\right)$ and glucose $\left(20 \mathrm{mg} \mathrm{mL}^{-1}\right)$ with an appropriate yeast concentration [optical density at $600 \mathrm{~nm}$ $\left.\left(\mathrm{OD}_{600}\right) \sim 0.1\right]$. Both samples were put on the orbital shaker at $300 \mathrm{rpm}$, and their concentrations were continuously monitored by the optical density at $600 \mathrm{~nm}$.

\section{Characterization}

Scanning electron microscopy (SEM) and corresponding elemental analysis were performed using a Hitachi SU8220 electron microscope. Transmission electron microscopy (TEM) images were recorded on a Tecnai G2 20 $\mathrm{S}$-TWIN electron microscope. Powder X-ray diffraction (PXRD) patterns were recorded on a Rigaku Corporation $\mathrm{X}$-ray powder diffractometer using $\mathrm{Cu} \mathrm{Ka}$ radiation $(\lambda=$ $1.54056 \AA$ ). CLSM was conducted on a single photon laser confocal imaging system Zeiss-710. The concentration of yeast cells was determined using an ultravioletvisible spectrophotometer, LAMBDA 650.

\section{RESULTS AND DISCUSSION}

Yeast cells have been recently reported to be used to adsorb heavy metal ions such as $\mathrm{Hg}^{2+}, \mathrm{Pb}^{2+}$, and $\mathrm{Cd}^{2+}$ because of the porous structure of mannosan, one of the major components that make up the cell wall of yeast cells. A previous study [39] has demonstrated that yeast cells adsorb $\mathrm{Zn}^{2+}$ using phosphatase in the cell wall. Based on the above reported results, a large number of $\mathrm{Zn}^{2+}$ would be adsorbed and distributed on the surface of yeast cell wall when yeast cells are suspended in $\mathrm{Zn}^{2+}$ aqueous solution, and the ZIF-8 shell would be produced when a solution of 2-methylimidazole is added. The PXRD pattern of the synthesized sample is the same as the corresponding simulated ZIF-8 XRD pattern (Fig. S1), indicating that the synthesized sample is ZIF-8 with high crystallinity.

The original shape of bare yeast cells is oval in culture solution. When dried at room temperature, the cells noticeably shrink due to dehydration and the oval shape of these cells changes. Therefore, bare yeast cells are dried in a cooling vessel for $4 \mathrm{~h}$, which can help in maintaining the original shape of cells before SEM images are taken. Fig. 1a shows the typical elliptical morphology of a bare single yeast cell of approximately $5 \mu \mathrm{m}$. The surface of the native yeast cell was very smooth, and the cell showed no shrinkage. After encapsulation, the surface of the yeast cell became very rough, and its shape was altered to be rather spherical (Fig. 1b). This result demonstrates the successful coating of the ZIF-8 shell onto the yeast cell to form a yeast@ZIF-8 core-shell composite structure. The mechanical strength of the ZIF-8 shell is great enough to resist dehydration and osmotic pressure.

An SEM cross-section was also taken to check whether the ZIF-8 shell thoroughly covers the surface of yeast cells. Fig. 1c shows one yeast cell encapsulated by a single ZIF-8 shell (between the red lines), the thickness of which is approximately $100 \mathrm{~nm}$. As for TEM observation, the native yeast cells are considerably shrunk due to dehydration of yeast cells on the copper grid (Fig. S2a). In 


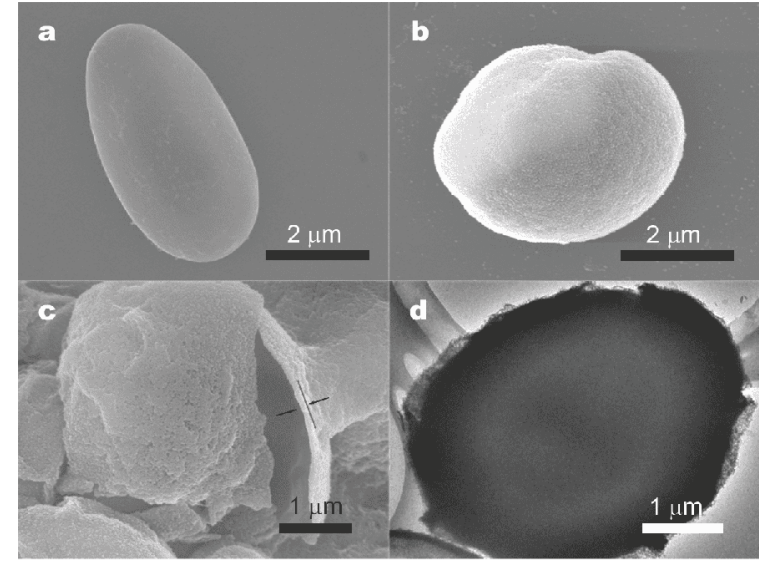

Figure 1 (a) SEM image of a single bare yeast cell and (b) a single cell coated with ZIF-8. (c) Cross-section SEM of yeast@ZIF-8 and (d) TEM image of a single yeast@ZIF-8.

contrast, the shape of the yeast@ZIF-8 composite structure is kept intact (Fig. 1d), highlighting its good mechanical stability. The magnified TEM image (Fig. S2b) clearly displays that the ZIF-8 shell comprises tiny nanoparticles of approximately $20 \mathrm{~nm}$. Elemental analysis by X-ray energy-dispersive spectroscopy disclosed that the outer shell of yeast cells comprises elements such as Zn, N, O, and C (Fig. S3), confirming that the outer shells are made up of ZIF-8.

For the direct observation of the yeast@ZIF-8 coreshell composite structure in the solution, two dyes, Alexa Fluor 647 and FUN 1, were used to stain the cells. Fig. 2ac show the CLSM bright-field images of yeast@ZIF-8 and the corresponding CLSM fluorescence images obtained by Alex Fluor 647 and FUN 1 staining, respectively. After encapsulation, yeast cells maintained their shape without any change compared with bare yeast cells (Fig. 2a). Under irradiation by laser light, the ZIF- 8 shell clearly manifested a vivid blue circle outside the surface of yeast cells (Fig. 2b). This result gives strong evidence on the full coating of the ZIF-8 shell on the surface of yeast cells. More importantly, the red fluorescence from FUN 1stained yeast cell cores suggested that yeast cells were alive even after encapsulation by ZIF-8 (Fig. 2c). Fig. 2d shows the superimposed image of Fig. $2 \mathrm{a}-\mathrm{c}$, which shows that all the red fluorescence yeast cell cores are coated by the blue ZIF-8 shell.

Considering that protection of the eggshell enables the fresh maintenance of eggs for a long period, the cell viability against time was first tested without any nutrients. The proliferation of yeast cells is controlled by specific growth factors and essential nutrients. If any of

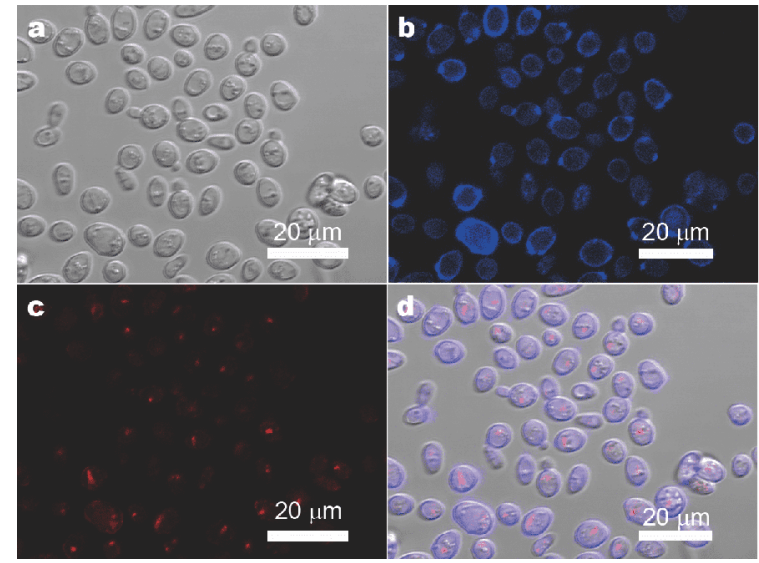

Figure 2 CLSM images of the yeast@ZIF-8 composite structure: (a) bright-field image, florescence images from Alexa Fluor 647 (b) and FUN 1 (c) staining, and (d) superimposed image of (a)-(c).

these signals is missing, then the cell enters into a special resting state-the stationary phase-and becomes inert. When yeast cells are encapsulated by minerals, it goes into a static state because the growth of encapsulated cells is not observed even in the nutrient medium [11]. Both the bare yeast cells and cells coated with ZIF-8 were suspended in DI water at $4^{\circ} \mathrm{C}$ for one month. The result is summarized in Fig. 3. The bare yeast cells very quickly lost their metabolic ability and almost died within one month because of the lack of nutrients. After coating with the ZIF- 8 shell, more than $80 \%$ of yeast cells remained alive in pure water even after one month (Fig. 3). The small amount of deaths among yeast@ZIF-8 cells may be because of the original defects on the shells (Fig. S4). The cell viability experiment verifies that the ZIF-8 shell can effectively prolong the life of encapsulated yeast cells because the ZIF- 8 shell blocks mass transport and energy transfer between the yeast cells and external environment. Moreover, because of the porous nature of the ZIF-8 shell, some extremely small molecules such as water and oxygen can penetrate and enter the inner shell. Considering the prolongation of the lifetime of the coated yeast cells, this ZIF-8 encapsulation strategy is very promising for cell storage.

Yeast cells are easily damaged and lose their viability under conditions such as high temperature, in the presence of lyase, and improper $\mathrm{pH}$ values. Zymolyase is frequently used to damage yeast cell walls because it contains not only protease with affinity for mannose glycoprotein but also $\beta$-1,3-glucanase that releases pentasaccharides from pachyman or laminarin. Both enzymes might lyse yeast cell walls, which causes cells to 


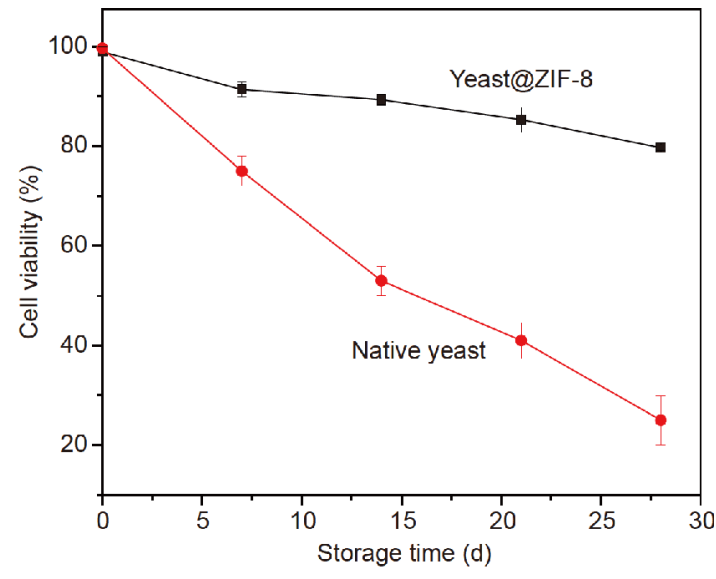

Figure 3 Cell viability versus storage time in pure water at $4^{\circ} \mathrm{C}$.
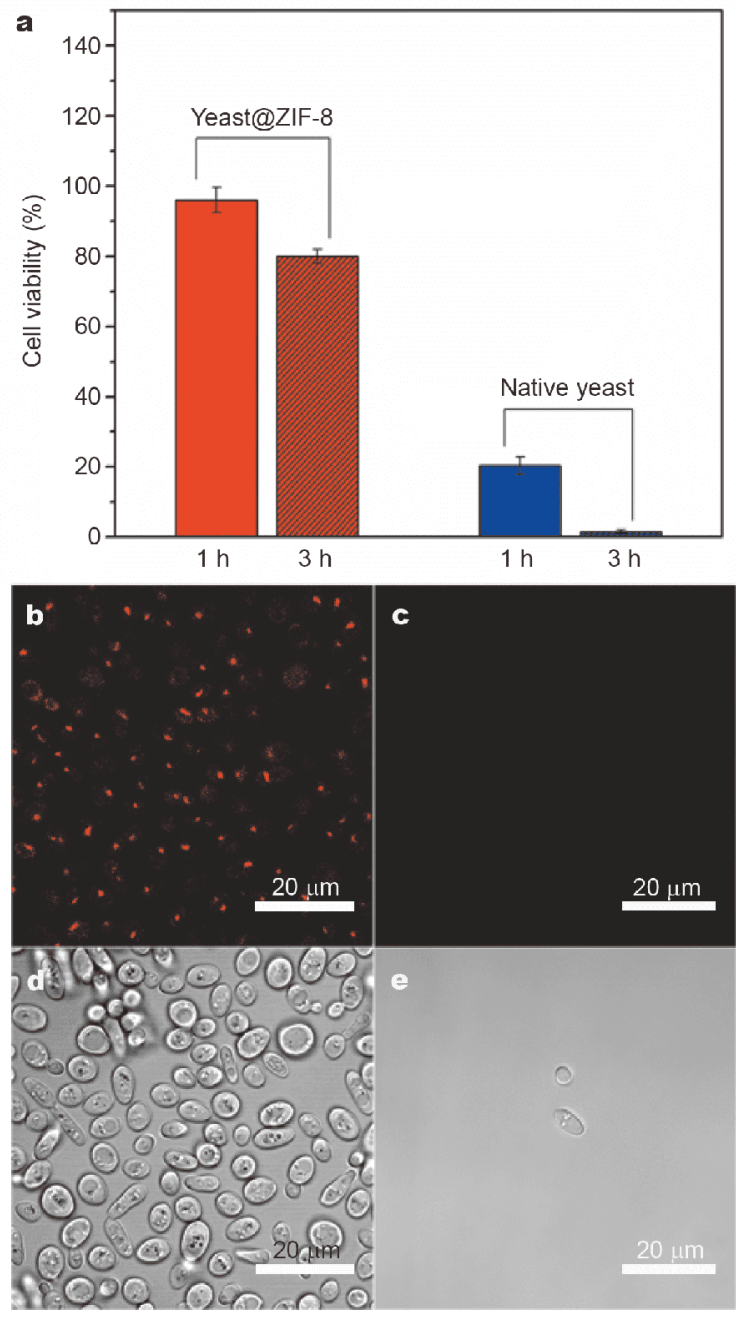

Figure 4 (a) Cell viability of the bare yeast cells and coated yeast cells in zymolyase solution for 1 and $3 \mathrm{~h}$, respectively; ( $b$ and d) CLSM images of the yeast@ZIF-8 composite structure in zymolyase solution for $3 \mathrm{~h}$; and (c and e) CLSM images of the bare yeast cells in zymolyase solution for $3 \mathrm{~h}$.

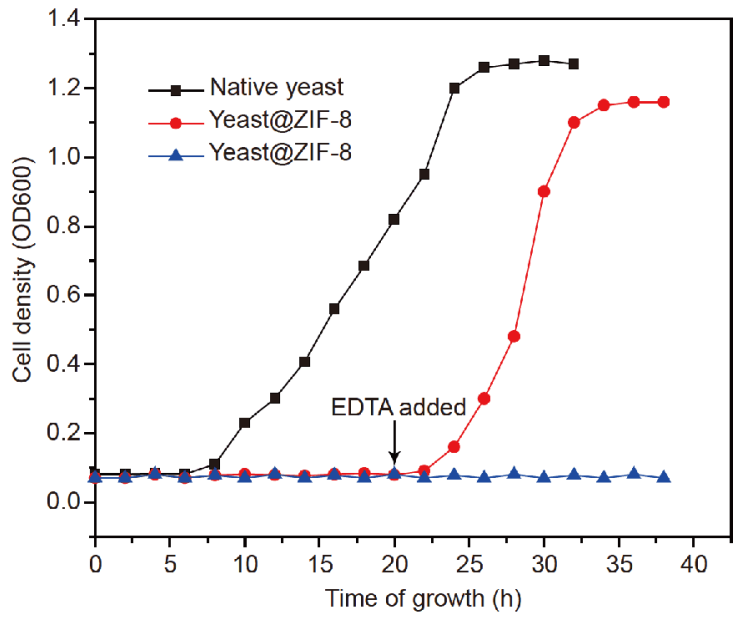

Figure 5 Growth curves of the yeast cells with and without shell in glucose solution.

lose their ability to maintain homeostasis, resulting in their bursting out without cell walls. Therefore, the protective effect of the ZIF-8 shell in the presence of zymolyase was tested in this study. Eighty percent of the bare yeast cells were dead after culture for $1 \mathrm{~h}$ (Fig. 4a), whereas almost all of them were damaged when the culture time exceeded $3 \mathrm{~h}$ (Fig. $4 \mathrm{c}$ and e). In contrast, only approximately $20 \%$ of the ZIF-8-coated yeast cells were dead after culture in zymolyase solution for $3 \mathrm{~h}$ (Fig. $4 \mathrm{a}$, $\mathrm{b}$, and $\mathrm{d}$ ). The death rate was very similar to that in pure water with 1 -month storage at $4^{\circ} \mathrm{C}$. This may be attributed to defects in the ZIF-8 shell by which zymolyase can contact yeast cells. In addition, the encapsulated yeast cells maintained their normal shape and size in the presence of zymolyase even after culture for $3 \mathrm{~h}$, highlighting that the ZIF-8 shell can retain the integrity of yeast cell walls by preventing their contact with outer zymolyase (Fig. $4 \mathrm{~b}$ and d). Although the ZIF-8 shell is porous, the pore size of ZIF- 8 is only $0.34 \mathrm{~nm}$, which is small enough for hindering the penetration of large zymolyase (dimension of $\beta$-1,3-glucanase is $8.7 \times 8.7 \times 15.6 \mathrm{~nm}^{3}$ ). This finding demonstrates that the ZIF- 8 shell can serve as an enhanced safeguard to protect living cells against foreign invasion.

The encapsulated yeast cells are easily reactivated by dissolving the ZIF-8 shell. As shown in Fig. 5, the yeast@ZIF-8 composite structure was maintained in an inert state in glucose solution at $30^{\circ} \mathrm{C}$, and there was no proliferation (blue curve). Upon the addition of EDTA, the stronger coordination interaction between EDTA and $\mathrm{Zn}^{2+}$ in ZIF-8 resulted in the decomposition and subsequent dissolution of the ZIF-8 shell. As a result, the 
growth of the coated yeast cells was triggered by the removal of the ZIF-8 shell (red curve). The proliferation curve of the reactivated cells was similar to that of the bare yeast cells (red and black curves), indicating that the biological functions and activity of yeast cells were unaffected by encapsulation and reactivation.

\section{CONCLUSIONS}

In summary, well-defined yeast@ZIF-8 composite structures in which single yeast cells are fully coated by the ZIF-8 shell with thickness of approximately $100 \mathrm{~nm}$ are easily synthesized under mild conditions. The coated yeast cells exhibit long-term viability in the absence of nutrients, good biochemical robustness under harsh conditions, and easy regeneration via the removal of protective shells. Therefore, it is expected that encapsulation of yeast cells by MOFs will become a novel and general strategy for improving the stability and functionality of microorganisms because of the rich type, convenient synthesis, and multiple functionality of various MOFs.

\section{Received 29 November 2018; accepted 14 December 2018; published online 18 January 2019}

1 Wang B, Liu P, Tang R. Cellular shellization: surface engineering gives cells an exterior. BioEssays, 2010, 32: 698-708

2 Léonard A, Dandoy P, Danloy E, et al. Whole-cell based hybrid materials for green energy production, environmental remediation and smart cell-therapy. Chem Soc Rev, 2011, 40: 860-885

3 Wang G, Li X, Mo L, et al. Eggshell-inspired biomineralization generates vaccines that do not require refrigeration. Angew Chem, 2012, 124: 10728-10731

4 Yang SH, Ko EH, Jung YH, et al. Bioinspired functionalization of silica-encapsulated yeast cells. Angew Chem, 2011, 123: 6239-6242

5 Yang SH, Lee KB, Kong B, et al. Biomimetic encapsulation of individual cells with silica. Angew Chem Int Ed, 2009, 48: 91609163

6 Park JH, Hong D, Lee J, et al. Cell-in-shell hybrids: chemical nanoencapsulation of individual cells. Acc Chem Res, 2016, 49: 792800

7 Li S, Dharmarwardana M, Welch RP, et al. Template-directed synthesis of porous and protective core-shell bionanoparticles. Angew Chem Int Ed, 2016, 55: 10691-10696

8 Krol S, del Guerra S, Grupillo M, et al. Multilayer nanoencapsulation. New approach for immune protection of human pancreatic islets. Nano Lett, 2006, 6: 1933-1939

9 Lee J, Choi J, Park JH, et al. Cytoprotective silica coating of individual mammalian cells through bioinspired silicification. Angew Chem Int Ed, 2014, 53: 8056-8059

10 Kempaiah R, Salgado S, Chung WL, et al. Graphene as membrane for encapsulation of yeast cells: protective and electrically conducting. Chem Commun, 2011, 47: 11480-11482

11 Wang B, Liu P, Jiang W, et al. Yeast cells with an artificial mineral shell: protection and modification of living cells by biomimetic mineralization. Angew Chem Int Ed, 2008, 47: 3560-3564
12 Fakhrullin RF, Minullina RT. Hybrid cellular-inorganic core-shell microparticles: encapsulation of individual living cells in calcium carbonate microshells. Langmuir, 2009, 25: 6617-6621

13 Ko EH, Yoon Y, Park JH, et al. Bioinspired, cytocompatible mineralization of silica-titania composites: thermoprotective nanoshell formation for individual Chlorella cells. Angew Chem Int Ed, 2013, 52: 12279-12282

14 Konnova SA, Sharipova IR, Demina TA, et al. Biomimetic cellmediated three-dimensional assembly of halloysite nanotubes. Chem Commun, 2013, 49: 4208-4210

15 Kuo WS, Wu CM, Yang ZS, et al. Biocompatible bacteria@Au composites for application in the photothermal destruction of cancer cells. Chem Commun, 2008, 45: 4430

16 Furukawa H, Cordova KE, O'Keeffe M, et al. The chemistry and applications of metal-organic frameworks. Science, 2013, 341: 1230444

17 Saliba D, Ammar M, Rammal M, et al. Crystal growth of ZIF-8, ZIF-67, and their mixed-metal derivatives. J Am Chem Soc, 2018, 140: $1812-1823$

18 Zhuang JL, Ceglarek D, Pethuraj S, et al. Rapid room-temperature synthesis of metal-organic framework HKUST-1 crystals in bulk and as oriented and patterned thin films. Adv Funct Mater, 2011, 21: $1442-1447$

19 Wang Z, Hu S, Yang J, et al. Nanoscale Zr-based MOFs with tailorable size and introduced mesopore for protein delivery. Adv Funct Mater, 2018, 28: 1707356

20 Qin JS, Yuan S, Lollar C, et al. Stable metal-organic frameworks as a host platform for catalysis and biomimetics. Chem Commun, 2018, 54: 4231-4249

21 Wang C, Liu X, Keser Demir N, et al. Applications of water stable metal-organic frameworks. Chem Soc Rev, 2016, 45: 5107-5134

22 Zhao M, Yuan K, Wang Y, et al. Metal-organic frameworks as selectivity regulators for hydrogenation reactions. Nature, 2016, 539: $76-80$

23 Zhao M, Deng K, He L, et al. Core-shell palladium nanoparticle@metal-organic frameworks as multifunctional catalysts for cascade reactions. J Am Chem Soc, 2014, 136: 1738-1741

24 Cai Y, Wu Y, Xuan T, et al. Core-shell Au@metal-organic frameworks for promoting raman detection sensitivity of methenamine. ACS Appl Mater Interfaces, 2018, 10: 15412-15417

$25 \mathrm{Wu}$ X, Xiong S, Mao Z, et al. A designed ZnO@ZIF-8 core-shell nanorod film as a gas sensor with excellent selectivity for $\mathrm{H}_{2}$ over CO. Chem Eur J, 2017, 23: 7969-7975

26 Zhan G, Fan L, Zhou S, et al. Fabrication of integrated $\mathrm{Cu}_{2} \mathrm{O} @ H K U S T-1 @ \mathrm{Au}$ nanocatalysts via galvanic replacements toward alcohols oxidation application. ACS Appl Mater Interfaces, 2018, 10: 35234-35243

27 Zhang D, Zhou W, Liu Q, et al. $\mathrm{CH}_{3} \mathrm{NH}_{3} \mathrm{PbBr}_{3}$ perovskite nanocrystals encapsulated in lanthanide metal-organic frameworks as a photoluminescence converter for anti-counterfeiting. ACS Appl Mater Interfaces, 2018, 10: 27875-27884

28 Luo F, Lin Y, Zheng L, et al. Encapsulation of hemin in metalorganic frameworks for catalyzing the chemiluminescence reaction of the $\mathrm{H}_{2} \mathrm{O}_{2}$-luminol system and detecting glucose in the neutral condition. ACS Appl Mater Interfaces, 2015, 7: 11322-11329

29 Liu G, Xu Y, Han Y, et al. Immobilization of lysozyme proteins on a hierarchical zeolitic imidazolate framework (ZIF-8). Dalton Trans, 2017, 46: 2114-2121

30 Doonan C, Riccò R, Liang K, et al. Metal-organic frameworks at the biointerface: synthetic strategies and applications. Acc Chem 
Res, 2017, 50: 1423-1432

31 Li P, Moon SY, Guelta MA, et al. Encapsulation of a nerve agent detoxifying enzyme by a mesoporous zirconium metal-organic framework engenders thermal and long-term stability. J Am Chem Soc, 2016, 138: 8052-8055

32 Lian X, Erazo-Oliveras A, Pellois JP, et al. High efficiency and long-term intracellular activity of an enzymatic nanofactory based on metal-organic frameworks. Nat Commun, 2017, 8: 2075

33 Chen WH, Vázquez-González M, Zoabi A, et al. Biocatalytic cascades driven by enzymes encapsulated in metal-organic framework nanoparticles. Nat Catal, 2018, 1: 689-695

34 Mehta J, Bhardwaj N, Bhardwaj SK, et al. Recent advances in enzyme immobilization techniques: Metal-organic frameworks as novel substrates. Coord Chem Rev, 2016, 322: 30-40

35 Tsumori N, Chen L, Wang Q, et al. Quasi-MOF: exposing inorganic nodes to guest metal nanoparticles for drastically enhanced catalytic activity. Chem, 2018, 4: 845-856

36 Lian X, Fang Y, Joseph E, et al. Enzyme-MOF (metal-organic framework) composites. Chem Soc Rev, 2017, 46: 3386-3401

37 Liang K, Richardson JJ, Doonan CJ, et al. An enzyme-coated metal-organic framework shell for synthetically adaptive cell survival. Angew Chem Int Ed, 2017, 56: 8510-8515
Liang K, Richardson JJ, Cui J, et al. Metal-organic framework coatings as cytoprotective exoskeletons for living cells. Adv Mater, 2016, 28: 7910-7914

39 Blackwell KJ, Singleton I, Tobin JM. Metal cation uptake by yeast: a review. Appl Microbiol Biotechnol, 1995, 43: 579-584

Acknowledgements This work was supported by the National Key Basic Research Program of China (2014CB931801 and 2016YFA0200700), the National Natural Science Foundation of China (2189038, 21721002 and 21475029), Frontier Science Key Project of Chinese Academy of Sciences (QYZDJ-SSW-SLH038), and K. C. Wong Education Foundation.

Author contributions Sun C and Chang L conceived the idea, proposed the strategy, designed and performed the experiments, analyzed the results and wrote the manuscript. Hou K helped writing and modifying the manuscript. Liu $\mathrm{S}$ and Tang $\mathrm{Z}$ supervised the project, helped design of experiments, evaluated the data and wrote the manuscript.

Conflict of interest The authors declare that they have no conflict of interest.

Supplementary information Supplementary data are available in the online version of the paper. 

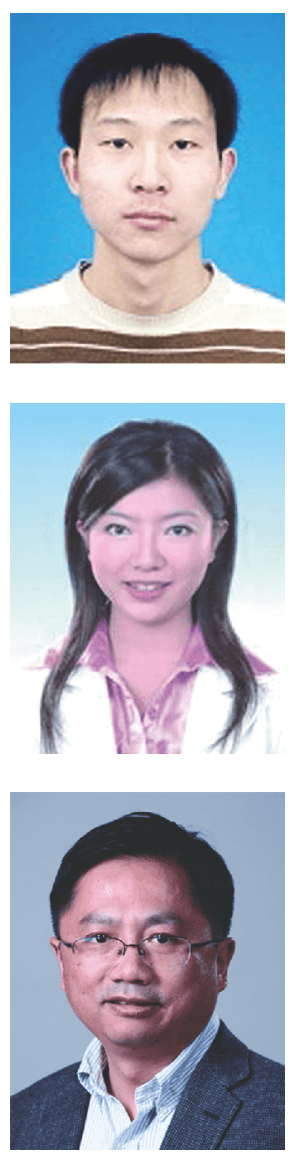

Chao Sun received his MSc degree in 2011 from Xinjiang University. Then he joined Tang's group at Harbin Institute of Technology in 2012. He is now a PhD student and his research interest focuses on the synthesis and applications of porous materials.
Lin Chang received her MSc degree in 2010 from Beijing University of Technology. Then she joined National Center for Nanoscience and Technology as an assistant engineer (2011-2014). Now she is an engineer and her research focuses on the synthesis and characterization of nanomaterials.
Zhiyong Tang obtained his PhD degree from the Chinese Academy of Sciences in 2000 under the direction of Professor Erkang Wang. After finishing his postdoctoral training at the Swiss Federal Institute of Technology, Zurich, and the Universtiy of Michigan, he returned to China and took a professor position at the end of 2006. His main research interest is focused on the preparation, assembly and applications of functional inorganic nanomaterials.

\section{金属有机框架材料包覆活细胞以保持其代谢活性}

孙超 ${ }^{1+}$, 常珠 ${ }^{2+}$, 侯珂 ${ }^{2}$, 刘绍琴 $^{3}$, 唐智勇 ${ }^{1,2^{*}}$

摘要 在本文中, 沸石型金属有机框架材料ZIF-8在温和的条件下被成功包覆于活细胞酿酒酵母表面. ZIF-8壳层展示出对酿酒酵母细胞明 显的保护作用. 与裸露酵母相比, 包覆酵母在 $4^{\circ} \mathrm{C}$ 纯水中可以保持更长时间的代谢活性. 当包覆酵母和裸露酵母在酵母裂解酶存在的溶液 中共同培养时, 包覆酵母仍然保持约 $80 \%$ 的活性, 而裸露酵母则几乎全部死亡. 除此之外, 用EDTA将ZIF-8壳层溶解之后, 包覆的酵母仍然 具有再生增殖能力, 且其生长曲线与裸露酵母类似. 